\title{
ЭПИДЕМИОЛОГИЧЕСКИЕ ОСОБЕННОСТИ РАКА ШЕЙКИ МАТКИ В ПРИМОРСКОМ КРАЕ
}

\section{EPIDEMIOLOGICAL FEATURES OF CERVICAL CANCER IN THE PRIMORSKY TERRITORY}

\section{Zhurman \\ T. Maslennikova \\ L. Matyushkina \\ E. Eliseeva}

Summary. Over the past decade, there has been a noticeable "rejuvenation" of pathology, an increase in the percentage of detection of this form of cancer in middle-aged and elderly women, which is due to a change in the age structure of women with an increase in the number of patients in older age groups. Analysis of statistics on cervical cancer in the Primorsky Territory. Materials and methods: annual reports of the Primorsky Territory Oncological Dispensary for 2008 and 2018.

Keywords: cervical cancer, incidence rate, malignant neoplasms, mortality, breast cancer.

\author{
Журман Варвара Николаевна \\ К.м.н., ГБУз «Приморский краевой онкологический \\ диспансер»; Ассистент, Тихоокеанский \\ государственный медицинский университет \\ varvara2007@yandex.ru \\ Масленникова Татьяна Юрьевна \\ Врач гинеколог-онколог, ГБУЗ «Приморский краевой \\ онкологический диспансер» \\ maslennikovatt@gmail.com \\ Матюшкина Людмила Семеновна \\ К.м.н., Тихоокеанский государственный медицинский \\ университет \\ doctor-Ism@yandex.ru \\ Елисеева Екатерина Валерьевна \\ Д.м.н., Тихоокеанский государственный медицинский \\ университет \\ yeliseeff23@gmail.com
}

Аннотация. Проведен анализ статистических данных по раку шейки матки в Приморском крае на основании годовых отчетов Приморского краевого онкологического диспансера за 2008 и 2018 гг. Полученные данные свидетельствуют об увеличении количества женщин среднего, пожилого и старческого возрастных групп с раком шейки матки в 2018 году по сравнению с 2008 годом, что может быть связано с увеличением продолжительности жизни, ростом заболеваемости данной патологией и увеличением количества выявленных случаев данного патологического процесса.

Ключевые слова: рак шейки матки, показатель заболеваемости, злокачественные новообразования, смертность, рак молочной железы.

(I-II) стадиях заболевание выявляется у 65,6\% пациенток. В структуре смертности от онкологических заболеваний в России в 2016 году среди женщин рак шейки матки составил 4,8\%, что соответствует 10-му месту. Летальность на первом году с момента установления диагноза составила 14,6\%. В возрастной группе 30-39 лет отмечается максимальная смертность от рака шейки матки (23,6\%) по сравнению с другими возрастными группами [4-7].

Предотвращение развития данной патологии возможно путем повышения осведомленности женской части населения, проведении регулярных профилактических осмотров и реализации скрининговых программ, направленных на выявление фоновых и предраковых заболеваний шейки матки $[8,9]$. 
Таблица 1. Динамика численности населения Приморского края в период с 2008 по 2018 годы, тысяч человек

\begin{tabular}{|l|l|l|l|l|l|}
\multirow{2}{*}{ Годы } & Численность населения, & В том числе & \multicolumn{2}{|l|}{ Доля в населении,\% } \\
\cline { 2 - 6 } & тысяч человек & 1507,6 & сельское & городское & сельское \\
\hline 2008 & 1988,6 & 1483,2 & 481,0 & 75,8 & 24,2 \\
\hline 2018 & 1923,1 & 439,9 & 77,1 & 22,9 \\
\hline
\end{tabular}

Таблица 2. Заболеваемость и смертность от рака шейки матки в Приморском крае в период с 2008 по 2018 годы, стандартизованный показатель на 100000 женского населения

\begin{tabular}{|l|l|l|l|l|}
\hline & \multicolumn{2}{|l|}{ Показатель заболеваемости } & \multicolumn{3}{l|}{ Показатель смертности } \\
\hline Год & 2008 & 2018 & 2008 & 2018 \\
\hline Рак шейки матки & 14,79 & 16,42 & 7,97 & 6,62 \\
\hline
\end{tabular}

В связи с этим актуальное значение имеет изучение динамики показателей рака шейки матки у женщин в Приморском крае.

\section{Цель анализа}

Анализ статистических данных по раку шейки матки у женщин в Приморском крае.

\section{Материалы и метолы}

Материалом для исследования явились годовые отчеты Приморского краевого онкологического диспансера за 2008 и 2018 гг. Математическую обработку результатов исследования выполняли с помощью пакета прикладных программ Statistica 6.0. Данные представлены в виде среднего арифметического значения М и ошибки среднего $\mathrm{m}$. Достоверность различий оценивали по t-критерию Стьюдента для независимых выборок. Для всех видов анализа статистически значимыми считали значения при $\mathrm{p}<0,05$.

\section{Результаты исслеАОвания}

В период с 2008 по 2018 годы отмечается уменьшение общей численности населения в Приморском крае на 65,5 тысяч человек, из них городское население уменьшилось на 24,4 и сельское на 41,1 тысяч человек (таблица 1).

В структуре заболеваемости злокачественными новообразованиями среди женщин Приморского края рак шейки матки в 2008 и 2018 годах занимает восьмое место, составляет 5,0\% и 4,0\% соответственно, третье место среди онкогинекологической патологии. В структуре смертности злокачественными новообразованиями среди женщин Приморского края рак шейки матки в 2008 и 2018 годах занимает восьмое место, составляет 5,0\% и десятое место 4,0\% соответственно, в 2008 году на втором месте среди онкогинекологической патологии и в 2018 году на третьем месте. Отмечается повышение стандартизованного показателя заболеваемости раком шейки матки на 100000 женского населения на 1,63 в 2018 году и снижения стандартизованного показателя смертности от рака шейки матки на 1,35 в 2018 году в Приморском крае (Таблица 2).

В 2008 году рак шейки матки I-ІІ стадии выявлен в 65,1\%, на III-IV стадии в 31,6\% случаев. В 2018 году на долю рак шейки матки I-ІІ стадии выявлен в 51,2\%, IIIIV стадии в $44,4 \%$ случаев.

Основным и наиболее информативным критерием качества, характеризующим деятельность онкологической службы, является общая выживаемость больных злокачественными новообразованиями. При этом своевременность выявления злокачественных новообразований среди населения наиболее полно характеризуется показателем одногодичной летальности, характеризующей долю больных, умерших до одного года с момента установления диагноза злокачественного новообразования. Отмечено повышение показателя одногодичной летальности на 2,5\% и показателя 5-летней выживаемости на 2,9\% в 2017 году (Рисунок 1).

В Приморском крае средний возраст заболевших раком шейки матки в 2008 году составил 50,8 лет, в 2018 году 52,1 года. Максимальное число заболевших наблюдается в возрастной группе 35-55 лет. Отмечается омоложение пациенток с выявленным раком шейки матки и увеличение количества женщин с раком шейки матки в возрасте от 20-24 лет. Увеличение количества пациенток старшей возрастной группы с раком шейки матки в 2018 году обусловлено увеличением продолжительности жизни, соответственно для 2008 и 2018 гг.: 2 пациента и 4 пациента 


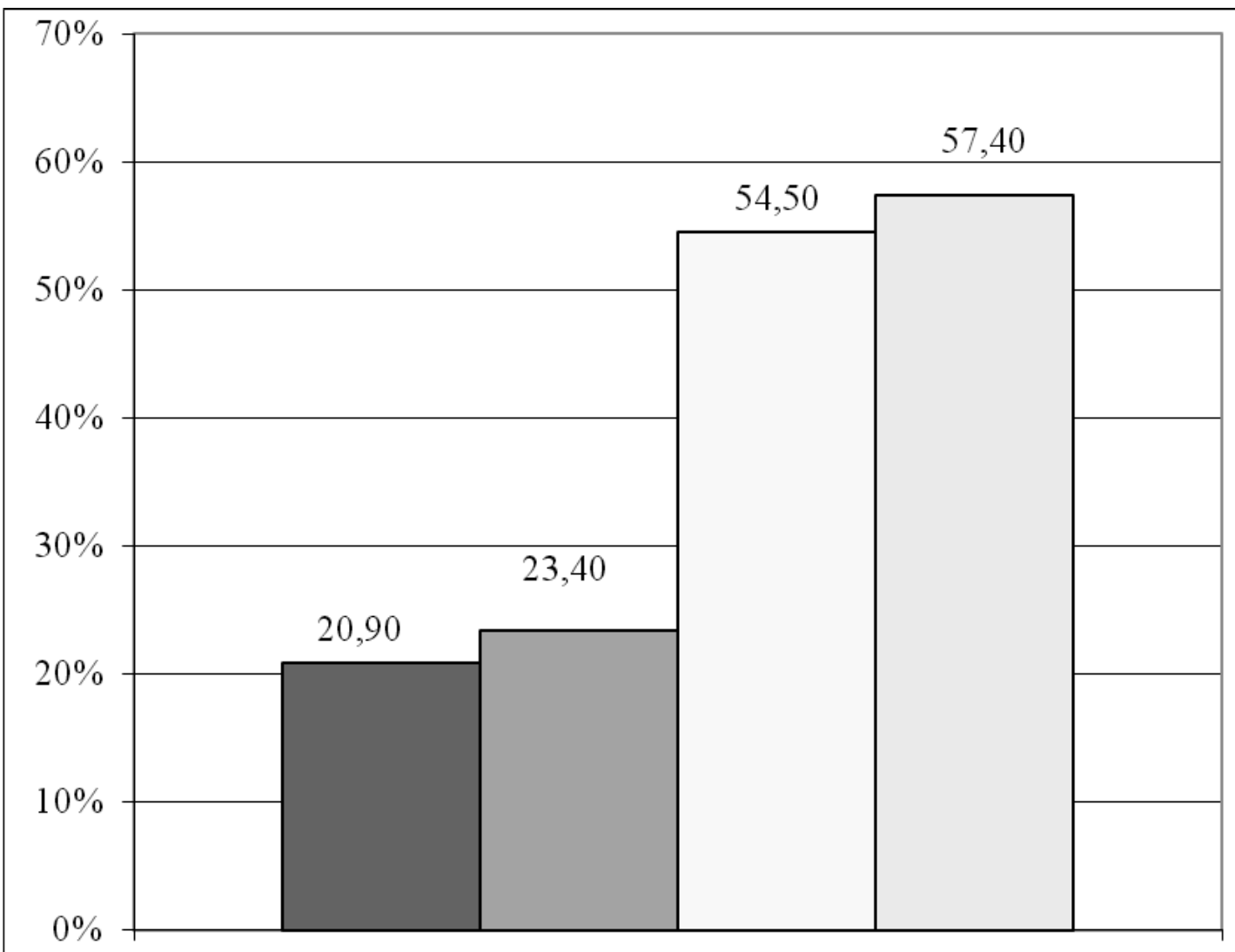

Рак шейки матки

Одногодичная летальность 2008 口Одногодичная летальность 2018 5-летняя выживаемость 2008

5-летняя выживаемость 2018

Рис. 1. Сравнительная характеристика показателей 5-летней выживаемости и одногодичной летальности у пациенток Приморского края, страдающих раком шейки матки, в 2008 и 2018 гг.

в возрастной категории 80-84 года; 2 пациента старше 85 лет зарегистрированы в 2018 году (Рисунок 2).

Примечание: возрастные диапазоны (лет) для рис. 2 и рис. 3: 1-20-24; 2-25-29; 3-30-34; 4-35-39; 5-40-44; 6-45-49; 7-50-54; 8-55-59; 9-60-64; 10-65-69; 11-70-74; 12-75-79; 13-80-84; 14-85 и более лет.

Согласно возрастной периодизации ВО3, распределение (в абсолютных числах) числа пациенток с раком шейки матки в 2008 и 2018 гг., представлено на рисунке 3.

Отмечается рост числа заболевших раком шейки матки с увеличением количества женщин среднего, пожилого и старческого возраста в 2018 году, вероятно связано с увеличением продолжительности жизни, ростом заболеваемости и увеличением количества выявленных случаев рака шейки матки.

Морфологическая верификация рака шейки матки в 2008 году составила 96,7\% и в 2018 году 96,4\%.

Динамика заболеваемости злокачественными новообразованиями у больных с впервые в жизни установленным диагнозом по городам и районам Приморского края в 2008 и 2018 гг. (на 100000 населения) представлена в таблице 3 .

Представленные данные свидетельствуют о повышении стандартизованного показателя заболеваемости раком шейки матки у женщин городов и районов Приморского края в период с 2008 по 2018 годы на 1,7 на 100000 женского населения. 


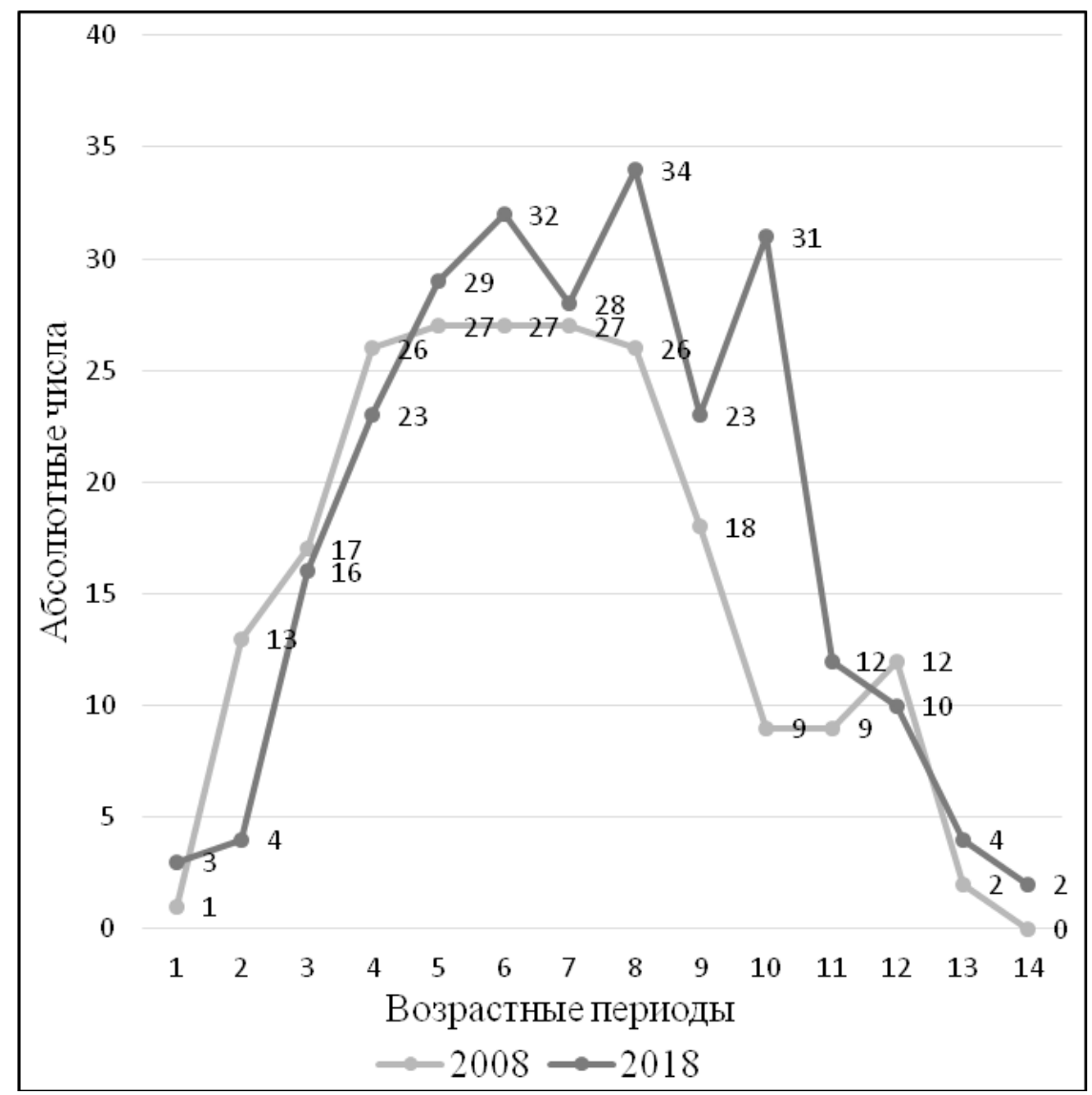

Рис. 2. Сравнительная характеристика пациенток (в абсолютных числах) в Приморском крае с раком шейки матки по возрастным периодам 2008 и 2018 гг.

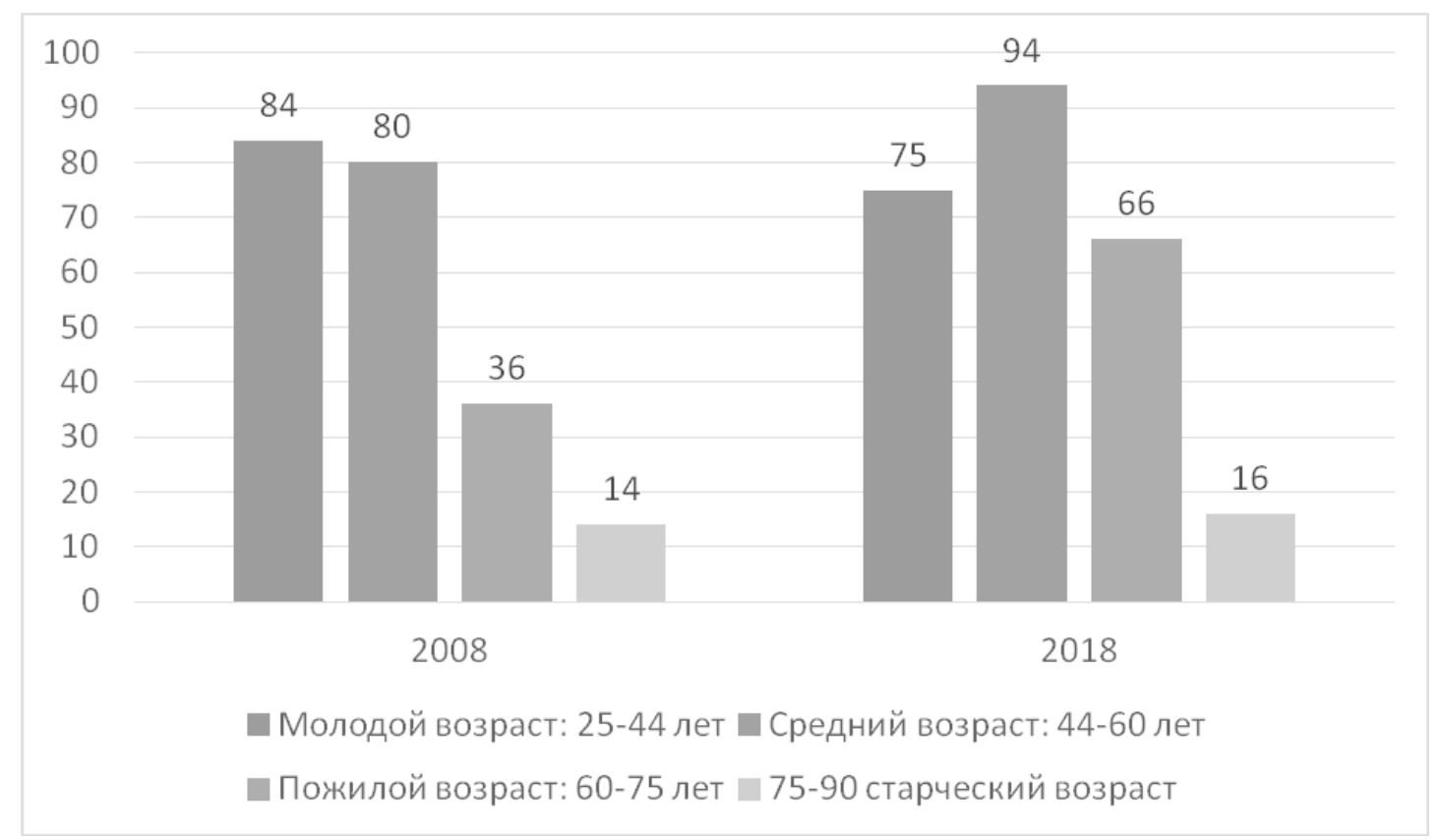

Рис. 3. Сравнительная характеристика числа пациенток в 2008 и 2018 годах (в абсолютных числах) с раком шейки матки, возрастная периодизация ВО3 
Таблица 3. Динамика заболеваемости злокачественными новообразованиями больных с впервые в жизни установленным диагнозом по городам и районам Приморского края в 2008 и 2018 гг. (стандартизованный показатель на 100000 населения)

\begin{tabular}{|c|c|c|c|}
\hline \multirow{2}{*}{ Города и районы } & \multicolumn{2}{|l|}{ Год } & \multirow{2}{*}{$\begin{array}{l}\text { Удаленность территории от г. Владивостока } \\
\text { км. }\end{array}$} \\
\hline & 2008 & 2018 & \\
\hline г. Арсеньев & 13,6 & 17,1 & 239,7 \\
\hline г. Артем & 12,5 & 13,8 & 48,8 \\
\hline г. Б. Камень & 0,0 & 17,6 & 115,5 \\
\hline г. Владивосток & 10,4 & 8,5 & 0 \\
\hline г. Дальнегорск & 12,4 & 11,6 & 495,0 \\
\hline г. Дальнереченск & 21,4 & 18,1 & 425,4 \\
\hline г. Лесозаводск & 2,0 & 9,2 & 371,0 \\
\hline г. Находка & 14,0 & 15,1 & 185,6 \\
\hline г. Партизанск & 14,0 & 11,1 & 173,9 \\
\hline г. Спасск & 17,3 & 21,9 & 247,1 \\
\hline г. Уссурийск & 14,3 & 15,2 & 98,7 \\
\hline г. Фокино & 18,1 & 22,2 & 130,8 \\
\hline Анучинский & 6,3 & 29,9 & 205,8 \\
\hline Кавалеровский & 10,5 & 24,7 & 425,0 \\
\hline Кировский & 12,8 & 10,5 & 272,0 \\
\hline Красноармейский & 4,9 & 5,9 & 484,0 \\
\hline Лазовский & 12,0 & 38,8 & 298,8 \\
\hline Михайловский & 13,7 & 23,1 & 124,2 \\
\hline Надеждинский & 7,7 & 5,2 & 66,6 \\
\hline Октябрьский & 12,8 & 21,8 & 95,0 \\
\hline Ольгинский & 0,0 & 10,5 & 444,0 \\
\hline Партизанский & 0,0 & 10,1 & 110,0 \\
\hline Пограничный & 3,9 & 13,3 & 233,9 \\
\hline Пожарский & 6,0 & 7,0 & 630,4 \\
\hline Спасский & 9,8 & 17,9 & 284,3 \\
\hline Тернейский & 14,1 & 8,8 & 821,5 \\
\hline Ханкайский & 3,6 & 13,5 & 236,7 \\
\hline Хасанский & 2,8 & 22,2 & 218,9 \\
\hline Хорольский & 18,1 & 3,6 & 167,4 \\
\hline Черниговский & 18,7 & 4,4 & 194,4 \\
\hline Чугуевский & 7,5 & 21,8 & 366,7 \\
\hline Шкотовский & 11,8 & 16,5 & 127,8 \\
\hline Яковлевский & 11,8 & 7,0 & 277,8 \\
\hline Приморский край & 14,7 & 16,4 & \\
\hline
\end{tabular}

Средний возраст умерших в Приморском крае от рака шейки матки в 2008 году 52,3 года, в 2018 году 55,4 лет.

Динамика смертности при злокачественных новообразованиях по городам и районам Приморского края в 2008 и 2018 гг. (на 100000 населения) представлена в таблице 4.

В целом у женщин Приморского края отмечается снижение стандартизованного показателя смертности от рака шейки матки в период с 2008 по 2018 годы на 1 на 100000 женского населения.

Динамика доли больных с IV клинической стадией из числа впервые и динамика одногодичной летальности выявленных по городам и районам Приморского края в 2008 и 2018 гг. (стандартизованный показатель на 100000 населения) представлена в таблицах 5 и 6.

Представленные данные свидетельствуют о повышении в 2018 году доли больных с IV клинической стадией 
Таблица 4. Динамика смертности от рака шейки матки по городам и районам Приморского края в 2008 и 2018 гг. (стандартизованный показатель на 100000 населения)

\begin{tabular}{|c|c|c|c|}
\hline \multirow[t]{2}{*}{ Города и районы } & \multicolumn{2}{|l|}{ Год } & \multirow{2}{*}{\begin{tabular}{|l} 
Удаленность территории \\
от г. Владивостока \\
км. \\
\end{tabular}} \\
\hline & 2008 & 2018 & \\
\hline г. Арсеньев & 8,5 & 11,4 & 239,7 \\
\hline г. Артем & 8,1 & 8,6 & 48,8 \\
\hline г. Б. Камень & 0,0 & 0,0 & 115,5 \\
\hline г. Владивосток & 5,3 & 3,8 & 0 \\
\hline г. Дальнегорск & 4,1 & 13,9 & 495,0 \\
\hline г. Дальнереченск & 21,4 & 20,7 & 425,4 \\
\hline г. Лесозаводск & 7,9 & 2,3 & 371,0 \\
\hline г. Находка & 10,5 & 5,9 & 185,6 \\
\hline г. Партизанск & 4,0 & 2,2 & 173,9 \\
\hline г. Спасск & 2,2 & 7,3 & 247,1 \\
\hline г. Уссурийск & 7,7 & 7,6 & 98,7 \\
\hline г. Фокино & 18,1 & 15,8 & 130,8 \\
\hline Анучинский & 12,5 & 14,9 & 205,8 \\
\hline Кавалеровский & 7,0 & 4,1 & 425,0 \\
\hline Кировский & 12,8 & 15,8 & 272,0 \\
\hline Красноармейский & 14,6 & 11,8 & 484,0 \\
\hline Лазовский & 6,0 & 23,3 & 298,8 \\
\hline Михайловский & 0,0 & 9,9 & 124,2 \\
\hline Надеждинский & 2,6 & 5,2 & 66,6 \\
\hline Октябрьский & 6,4 & 10,9 & 95,0 \\
\hline Ольгинский & 0,0 & 10,5 & 444,0 \\
\hline Партизанский & 13,6 & 10,1 & 110,0 \\
\hline Пограничный & 3,9 & 13,3 & 233,9 \\
\hline Пожарский & 9,0 & 3,5 & 630,4 \\
\hline Спасский & 6,5 & 7,2 & 284,3 \\
\hline Тернейский & 0,0 & 0,0 & 821,5 \\
\hline Ханкайский & 0,0 & 4,5 & 236,7 \\
\hline Хасанский & 2,8 & 0,0 & 218,9 \\
\hline Хорольский & 9,0 & 7,2 & 167,4 \\
\hline Черниговский & 8,0 & 9,0 & 194,4 \\
\hline Чугуевский & 18,8 & 17,5 & 366,7 \\
\hline Шкотовский & 3,9 & 16,5 & 127,8 \\
\hline Яковлевский & 5,9 & 7,0 & 277,8 \\
\hline Приморский край & 7,9 & 6,6 & \\
\hline
\end{tabular}

из числа впервые выявленных по городам и районам Приморского края в период с 2008 по 2018 годы на 4,5 на 100000 женского населения.

\section{Обсужление полученных $\Delta$ анных}

Статистические данные, согласно литературным источникам, свидетельствуют о росте заболеваемости и смертности от рака шейки матки. В последнее десятилетие отмечается тенденция более ранней выявля- емости злокачественных новообразований женской половой сферы, что может быть обусловлено лучшей диагностикой, ее доступностью, развитием и внедрением в медицинскую практику государственных программ по скринингу и ежегодному обследованию населения (с особенным вниманием к лицам, старше 40 лет) [2, 4, 5].

В настоящее время заметно повышение заболеваемости раком шейки матки у женщин до 29 лет - ежегодный прирост составляет 2,1\%. Подобная тенденция 
Таблица 5. Динамика пациентов с IV клинической стадией рака шейки матки из числа впервые выявленных по городам и районам Приморского края в 2008 и 2018 гг. (стандартизованный показатель на 100000 населения)

\begin{tabular}{|c|c|c|c|}
\hline \multirow[t]{2}{*}{ Города и районы } & \multicolumn{2}{|l|}{ Год } & \multirow{2}{*}{$\begin{array}{l}\text { Удаленность территории } \\
\text { от г. Владивостока } \\
\text { км. }\end{array}$} \\
\hline & 2008 & 2018 & \\
\hline г. Арсеньев & 14,3 & 33,3 & 239,7 \\
\hline г. Артем & 8,3 & 12,5 & 48,8 \\
\hline г. Б. Камень & 0,0 & 14,3 & 115,5 \\
\hline г. Владивосток & 16,1 & 7,4 & 0 \\
\hline г. Дальнегорск & 16,7 & 0,0 & 495,0 \\
\hline г. Дальнереченск & 0,0 & 14,3 & 425,4 \\
\hline г. Лесозаводск & 0,0 & 0,0 & 371,0 \\
\hline г. Находка & 8,7 & 13,6 & 185,6 \\
\hline г. Партизанск & 57,1 & 25,0 & 173,9 \\
\hline г. Спасск & 16,7 & 22,2 & 247,1 \\
\hline г. Уссурийск & 3,8 & 20,0 & 98,7 \\
\hline г. Фокино & 0,0 & 14,3 & 130,8 \\
\hline Анучинский & 0,0 & 25,0 & 205,8 \\
\hline Кавалеровский & 0,0 & 0,0 & 425,0 \\
\hline Кировский & 0,0 & 0,0 & 272,0 \\
\hline Красноармейский & 0,0 & 0,0 & 484,0 \\
\hline Лазовский & 50,0 & 20,0 & 298,8 \\
\hline Михайловский & 0,0 & 14,3 & 124,2 \\
\hline Надеждинский & 0,0 & 50,0 & 66,6 \\
\hline Октябрьский & 0,0 & 0,0 & 95,0 \\
\hline Ольгинский & 0,0 & 0,0 & 444,0 \\
\hline Партизанский & 0,0 & 0,0 & 110,0 \\
\hline Пограничный & 0,0 & 0,0 & 233,9 \\
\hline Пожарский & 0,0 & 0,0 & 630,4 \\
\hline Спасский & 0,0 & 0,0 & 284,3 \\
\hline Тернейский & 0,0 & 0,0 & 821,5 \\
\hline Ханкайский & 0,0 & 0,0 & 236,7 \\
\hline Хасанский & 0,0 & 0,0 & 218,9 \\
\hline Хорольский & 16,7 & 50,0 & 167,4 \\
\hline Черниговский & 0,0 & 0,0 & 194,4 \\
\hline Чугуевский & 0,0 & 20,0 & 366,7 \\
\hline Шкотовский & 0,0 & 0,0 & 127,8 \\
\hline Яковлевский & 0,0 & 0,0 & 277,8 \\
\hline Приморский край & 7,6 & 12,1 & \\
\hline
\end{tabular}

к увеличению заболеваемости у женщин репродуктивного периода отмечается и в других странах. Так, в США, по данным Американского онкологического общества, на 2012 год 47\% больных раком шейки матки составляли женщины до 35 лет $[1,10,11]$.

Анализ нашей работы показал увеличение количества пациенток в возрасте 20-24 лет с раком шейки матки.
Отмечается увеличение в 2018 году впервые выявленных пациенток с раком шейки матки III-IV стадии на 12,8\%, что обусловлено доступностью диагностического обследования, внедрению программ диспансеризации.

В развитых странах отмечается значительное снижение смертности от рака шейки матки, что объясняется 
Таблица 6. Динамика одногодичной летальности от рака шейки матки по городам и районам Приморского края в 2008 и 2018 гг. (стандартизованный на 100000 населения)

\begin{tabular}{|c|c|c|c|}
\hline \multirow[t]{2}{*}{ Города и районы } & \multicolumn{2}{|l|}{ Год } & \multirow{2}{*}{$\begin{array}{l}\text { Удаленность территории } \\
\text { от г. Владивостока } \\
\text { км. } \\
\end{array}$} \\
\hline & 2008 & 2018 & \\
\hline г. Арсеньев & 0,0 & 33,3 & 239,7 \\
\hline г. Артем & 11,8 & 12,5 & 48,8 \\
\hline г. Б. Камень & 0,0 & 50,0 & 115,5 \\
\hline г. Владивосток & 27,5 & 24,6 & 0 \\
\hline г. Дальнегорск & 40,0 & 20,0 & 495,0 \\
\hline г. Дальнереченск & 18,2 & 50,0 & 425,4 \\
\hline г. Лесозаводск & 28,6 & 0,0 & 371,0 \\
\hline г. Находка & 47,1 & 12,5 & 185,6 \\
\hline г. Партизанск & 50,0 & 33,3 & 173,9 \\
\hline г. Спасск & 40,0 & 0,0 & 247,1 \\
\hline г. Уссурийск & 7,1 & 29,6 & 98,7 \\
\hline г. Фокино & 50,0 & 37,5 & 130,8 \\
\hline Анучинский & 100,0 & 0,0 & 205,8 \\
\hline Кавалеровский & 33,3 & 0,0 & 425,0 \\
\hline Кировский & 0,0 & 50,0 & 272,0 \\
\hline Красноармейский & 0,0 & 50,0 & 484,0 \\
\hline Лазовский & 0,0 & 0,0 & 298,8 \\
\hline Михайловский & 0,0 & 25,0 & 124,2 \\
\hline Надеждинский & 50,0 & 16,7 & 66,6 \\
\hline Октябрьский & 0,0 & 28,6 & 95,0 \\
\hline Ольгинский & 0,0 & 0,0 & 444,0 \\
\hline Партизанский & 0,0 & 16,7 & 110,0 \\
\hline Пограничный & 0,0 & 0,0 & 233,9 \\
\hline Пожарский & 0,0 & 40,0 & 630,4 \\
\hline Спасский & 25,0 & 50,0 & 284,3 \\
\hline Тернейский & 0,0 & 0,0 & 821,5 \\
\hline Ханкайский & 0,0 & 0,0 & 236,7 \\
\hline Хасанский & 50,0 & 33,3 & 218,9 \\
\hline Хорольский & 66,7 & 25,0 & 167,4 \\
\hline Черниговский & 0,0 & 30,0 & 194,4 \\
\hline Чугуевский & 100,0 & 100,0 & 366,7 \\
\hline Шкотовский & 0,0 & 33,3 & 127,8 \\
\hline Яковлевский & 50,0 & 33,3 & 277,8 \\
\hline Приморский край & 23,7 & 23,4 & \\
\hline
\end{tabular}

увеличением количества своевременно выявленных случаев заболевания [11-13].

В Приморском крае также продемонстрировано снижение стандартизованного показателя смертности от рака шейки матки в период с 2008 по 2018 годы на 1 на 100000 женского населения.

Увеличение доли пациенток среднего и пожилого возраста в 2018 году в Приморском крае, как и в целом по территории России, объясняется повышением про- цента своевременно выявленных случаев заболевания и увеличением средней продолжительности жизни.

\section{Bыво}

Данные, полученные при статистическом анализе ситуации о раке шейки матки среди женщин Приморского края требуют дальнейшего совершенствования внедрения эффективных методов диспансеризации и профилактических мероприятий, скрининговых программ для оптимального планирования рациональной тактики лечения пациентов. 


\section{ЛИТЕРАТУРЫ}

1. Каприн А.Д, Старинский В.В., Петрова Г.В.Злокачественные новообразования в России в 2014 году (заболеваемость и смертность). М.: МНИои им. П. А. Герцена, филиал ФГБУ «НМИРЦ» Минздрава России, 2016. 250 с.

2. Аксель Е. М. Заболеваемость и смертность от злокачественных новообразований органов женской репродуктивной системы в России // Онкогинекология. 2015. № 1. С. 6-14.

3. Ferlay J., Soerjomataram I., Dikshit R., Eser S., Mathers C., Rebelo M., Bray F. Cancer incidence and mortality worldwide: Sources, methods and major patterns in GLOBOCAN2012 // International Journal of Cancer. 2015. No 136 (5). Pp. 359-386.

4. Fitzmaurice C., Dicker D., Pain A., Hamavid H., Moradi-Lakeh M., Maclntyre M.F., Wolfe C. The global burden of cancer 2013 // JAMA Oncology. 2015. No 1 (4). Pp. 505-527.

5. Vaccarella S., Laversanne M., Ferlay J., Bray F. Cervical cancer in Africa, Latin America and the Caribbean, and Asia: Regional inequalities and changing trends // International Journal of Cancer. 2017. No 141 (10). Pp. 1997-2001.

6. Каприн А.Д., Старинский В. В., Петрова Г. В. Злокачественные новообразования в России в 2016 г. (заболеваемость и смертность). М.: МНИОИ им. П. А. Герцена — филиал ФГБУ «НМИЦ радиологии» Минздрава России, 2018. 250 с.

7. Комарова Л. Е. Маммографический скрининг (состояние вопроса и перспективы) // Российский онкологический журнал. 2015. \# 20 (4). С. 9-15.

8. Абузарова Г.Р., Алексеев Б. Я., Антипов В. А. и др. Онкология: клинические рекомендации. М.: ГЭОТАР-Медиа, 2009. 960 с.

9. Ворошина Н.В., Важенин А. В., Тюков Ю. А. Заболеваемость злокачественными новообразованиями визуальных локализаций репродуктивной системы у женщин фертильного возраста Челябинской области // Онкология. Журнал им. П. А. Герцена. 2019. № 8 (2). С. 100-104. D0l: https://doi.org/10.17116/ onkolog20198021100

10. Tolkushin A.G., Zyryanov S. K., Pogudina N. L., Davydovskaya M.V. Clinical and economic studies on pharmacotherapy of malignant neoplasms: the modeling approach // Farmakoekonomika. Modern Pharmacoeconomic and Pharmacoepidemiology. 2018. № 11 (4). Pp. 48-60.

11. Akinyemiju T., Ogunsina K., Sakhuja S., Ogbhodo V., Braithwaite D. Life-course socioeconomic status and breast and cervical cancer screening: Analysis of the WH09s Study on Global Ageing and Adult Health (SAGE) // BMJ Open. 2016. № 6 (11). Pp. 012753.

12. Ibfelt E., Kjaer S., Høgdall C., Steding-Jessen M., Kjaer T., Osler M., Dalton S. O. Socioeconomic position and survival after cervical cancer: Influence of cancer stage, comorbidity and smoking among Danish women diagnosed between 2005 and 2010 // British Journal of Cancer. 2013. № 109 (9). Pp. $2489-2495$.

13. Kim J.-Y., Kang H.-T. Association between Socioeconomic Status and Cancer Screening in Koreans over 40 Years in Age Based on the 2010-2012 Korean National Health and Nutrition Examination Survey // Korean Journal of Family Medicine. 2016. № 37 (5). Pp. 287-292.

\footnotetext{
( Ж Журман Варвара Николаевна ( varvara2007@yandex.ru ), Масленникова Татьяна Юрьевна ( maslennikovatt@gmail.com ), Матюшкина Людмила Семеновна ( doctor-Ism@yandex.ru ), Елисеева Екатерина Валерьевна ( yeliseeff23@gmail.com ).

Журнал «Современная наука: актуальные проблемы теории и практики»
} 